\title{
(Re)Building Çatalhöyük: Changing Virtual Reality in Archaeology
}

\author{
Colleen L. Morgan, University of California, Berkeley, \\ Berkeley, CA, USA \\ E-mail: clmorgan@berkeley.edu
}

\begin{abstract}
Building virtual models of archaeological sites has been seen as a legitimate mode of representing the past, yet these models are too often the end product of a process in which archaeologists have relatively limited engagement. Instead of building static, isolated, uncanny, and authorless reconstructions, I argue for a more active role for archaeologists in virtual reconstruction and address issues of representational accuracy, personal expression in avatars and peopling the virtual past. Interactive virtual worlds such as Second Life provide tools and an environment that archaeologists can use to challenge static modes of representation and increases access to non-expert participants and audiences. The virtual model of Çatalhöyük in Second Life is discussed as an ongoing, multivocal experiment in building, rebuilding, and representing the past and present realities of the physical site.
\end{abstract}

Résumé: Le fait de construire des modèles de sites archéologiques a été perçu comme un mode légitime de représentation du passé, cependant ces modèles sont trop souvent le produit final d'un processus dans lequel les archéologues ont un engagement limité. Au lieu de construire des reconstitutions statiques, isolées, étranges et anonymes, je soutien un rôle plus actif de reconstitution virtuelle pour les archéologues et pose les problèmes de l'exactitude figurative, l'expression personnelle dans les avatars et vulgarisant le passé virtuel. Les mondes virtuels interactifs tels que «Second Life»fournissent des outils et un environnement que les archéologues peuvent utiliser pour défier les modes statiques de représentation et augmente l'accès aux participants non experts et au public. Le modèle virtuel de Çatalhöyük dans «Second Life»est discuté comme une expérience multi-vocale en cours de construction, de reconstruction, qui représente les réalités du passé et du présent du site physique.

Resumen: La construcción de modelos virtuales de los yacimientos arqueológicos se considera un modo legítimo de representar el pasado, sin 
embargo, estos modelos son, con demasiada frecuencia, el producto final de un proceso en que los arqueólogos han limitado relativamente su compromiso. En lugar de elaborar reconstrucciones estáticas, aisladas, extrañas y anónimas, defiendo un papel más activo para los arqueólogos en la reconstrucción virtual y abordo cuestiones relacionadas con la exactitud, la expresión personal en avatares y la población del pasado virtual. Los mundos virtuales interactivos, como Second Life, ofrecen herramientas y un entorno que los arqueólogos pueden utilizar para desafiar los modos estáticos de representación y amplían el acceso a los participantes y a las audiencias no expertas. El modelo virtual de Çatalhöyük en Second Life se discute como un experimento multivocal y continuo para la construcción, la reconstrucción y la representación de las realidades pasada y presente del yacimiento físico.

\section{KEY WORDS}

Second Life, Virtual reality, Çatalhöyük, Outreach

\section{Introduction}

Virtual reality has been a popular visualization tool within the realm of archaeological computing, as evident from the number of books, journals, and conferences dedicated to the subject. Though often presented as a single entity, virtual reality represents more of a spectrum, from the fully immersive environments famously posited in William Gibson's Neuromancer to the space "where you are when you're talking on the phone" (Rucker et al. 1992), that is, not quite in the room where you are now and not with the person to whom you are speaking, but somewhere in-between (Mirzoeff 1999). Goldberg (1998) further disambiguates this concept by contrasting virtual reality with what Pat Gunkel terms as "telepresence;" with the distance between being divided by a "deep chasm" (33). This difference has also been characterized primarily as a contrast between imagebased immersive environments as opposed to virtual networks, which are text based (Lister et al. 2002:35). An extensive examination of the technological, the visual, and the artistic foregrounding of virtual reality is outside the purview of this article, but a brief outline of this mixed lineage situates virtual reality as it is used in archaeology. This outline is followed by a potential future course for virtual archaeology as an interpretive tool and venue for public outreach within the realm of Second Life. 


\section{Virtual Reality}

The origins of the technology of immersive virtual reality can be traced to Sutherland's experiments in generating a virtual flight simulator (1968). He succeeded in presenting a Cartesian grid to subjects wearing a "headmounted three dimensional display", a "concept of space which is historically and culturally specific to Western art and science" (Lister et al. 2002:114). The actual term "virtual reality" was first used by Jaron Lanier in 1979 (Goldberg 1998:33), but the concept was most vividly brought to the public's attention by the cyberpunk genre of science fiction, in which characters negotiated realities so immersive that actions inside the virtual world would physically affect their real bodies (see William Gibson, Rudy Rucker, and Neal Stephenson among many others). This early, ambitious envisioning of a complete virtual world inevitably led to disappointment and disillusionment with the idea as the real world implementations failed to meet the hyped expectation. One historian of visual media describes first becoming aware of an increasing divide between hype and reality at an 1989 SIGGRAPH industry event where virtual reality was being discussed at many panels. At one of the panels, Jaron Lanier described virtual reality as being "an open world where your mind is the only limitation", however the subsequent demonstration of a two-player virtual reality game of squash, was a "very poor illusion of "reality" (Woolley 1992:14-15). The rhetoric of the event and of virtual reality in general was overblown, though, as Woolley notes, the technology of the first television broadcasts and films were similarly crude. These early developers, working in 'blue sky' environments, were not subject to academic controls and formed a community of entrepreneur technologists more akin to an artistic movement (18). This enthusiasm for virtuality was matched in the public sector after the 1992 release of Lawnmower Man, which dramatized a 'cybersex' scene, where the virtual bodies of the man and the woman involved became abstractions that melt into each other, while their physical bodies remain separate (Manovich 2001:110-111). When this eventuality was not immediately available, the hype waned in the face of a more accessible, if arguably less immersive technology: the World Wide Web (Hillis 2006).

While the promise of virtual reality (VR), that is, photo-realistic, full sensory immersion, has not been immediately forthcoming, it has elicited a tremendous amount of attention in public and academic realms. The origins of conceptual VR are seen as coming from different sources; Jonathan Crary cites the camera obscura as an object which originally intended to stimulate philosophical reflection and speculation on the nature of perception and knowledge, the external world, and the eye and the brain, rather than a curiosity that simply produced images like a camera without film 
(1990:29). Others have likened VR to "stepping through Alberti's window" (Robins 1996), a reference to a 15th-century perspectival painter; being swallowed by television (Dery and Lamantia 1993); or to "passing through the movie screen to enter the fictional world of the "film" (Morse 1998). In this context, VR seems to be less of a "radical break" in the history of art and technology than a continuation of existing historical trajectories (Lister et al. 2002:125).

Telepresence, or virtual reality that originates from online, text-based networks, is more closely related to the literature-based genre of hypertext and is more broadly used than immersive virtual reality, yet it remains, for the most part, under-theorized. Early ventures into the world of text-based telepresence include interactive fiction games, wherein computer users explore worlds described textually with commands such as "run" or "open the mailbox" to solve mysteries or complete journeys. Following these early adventures were Multi-User Dungeons and MUD Object Oriented (MUDs and MOOs). These are text-based adventures that many users can access simultaneously, adding a level of interactivity between players and their environment. Within the larger field of virtual ethnography there are a number of studies of MUDs (Hine 2000) that explore identity building in these online venues (Bassett 1997; Kendall 1998). These text-based games are not the only examples of telepresence; additional instances of socially constructed worlds are online communities such as The WELL and chatrooms (Hine 2000), yet I would argue that these operate outside of a simulated landscape and are further away on the spectrum from immersive virtual reality. MUDs and MOOs are more directly connected to later Massively, Multi-player Online Role-Playing Games (MMORPGs), a large genre in the computer gaming industry. Most of these gaming formats remain largely unexplored within academic archaeology, with the exception of Second Life, which is covered at length below.

\section{Virtual Archaeology}

Virtual reality in archaeology, or "virtual archaeology" (Reilly 1990), encompasses the modeling of landscapes, excavations, buildings, cities, and environments built with a variety of computer applications in order to test scientific questions, communicate impressions of the past to others, and invite outside participation in the construction of the past. Virtual reconstructions of the past have been compelling for archaeologists as a method to capture the interest of a public who wanted, in their perception, to relive the past as accurately as possible. From the full-color, oversized text, Virtual Archaeology: "The object of this book...is to offer to the reader the most faithful re-presentation of the ancient world possible: highly realistic 
information and with a high scientific content" (Forte and Siliotti 1997:10). The book provides a long list of virtual reconstructions of archaeological sites built in the mid-1990s, though the term "virtual" in this context is used very loosely to describe any site that has been reconstructed by digital means.

Like the main body of research in VR, virtual archaeology can be divided into immersive and conceptual categories. The Southampton York Archaeological Simulation System project (SYASS) attempted to produce "the archaeological equivalent of a flight simulator" (Reilly 1992:163), which allowed students to experience an excavation before performing these destructive techniques on site. Unfortunately, without experience at an actual site, students had a hard time grasping excavation concepts such as 'context, spit, phase, horizon, and locus' (see also Benko et al. 2004). In another project in 1997, Frischer established the Cultural Visualization Lab at UCLA where archaeology and digital modeling were taught simultaneously, but for the most part, during the 1990s, archaeologists were not involved in many of the archaeological reconstructions, wherein "rarely, if ever, are we told who made the model, whether there was any consultation between the modelmaker and the archaeologists, and what elements of the model are known with certainty and which are hypothetical" (Frischer et al. 2002:10). Efforts to recreate Pompeii, for example, were seen as "disturbing, and uncanny, sometimes cheesy and slick" and the touted verisimilitude was absent, as "painted panels along the periphery of the reconstructed sanctuary were unsettling to many precisely because they had been filched from other Roman cities" (ibid 11). For all the realism the reconstructions intended to convey, most models were clean, well lit, and utterly depopulated. The user could then "fly" through the model, traveling at speeds optimal for disguising crude graphics, but that no actual inhabitant of these cities would have experienced. After this criticism of virtual Pompeii, Frischer's team (now called the Experiential Technologies Center) has created an uncanny, slick, digital Rome where the user "flies through" column-lined streets.

The broader shift in virtual reality research from immersive to conceptual VR is also apparent in the changes in archaeological reconstructive projects of the late 1990s and early 2000s. The goggles and gloves of immersive VR were seen as too restrictive and bulky and graphics rendering was still too primitive and unwieldy for broad use (Kantner 2000). And while there is some attention to theoretical concerns (Goodrick and Gillings 2000), sustainability (Krasniewicz 2000), transparency (Lock 2003), and pedagogical usefulness (Slator et al. 2001; Terras 1999), most reconstructions of sites were built without clear archaeological goals and questions in mind. Ultimately, immersive VR in archaeology stalled, and while some archaeologists attributed this to misconceptions about technical 
difficulty and expense (Goodrick and Earl 2004), it can more likely be attributed to the rise in interest in the World Wide Web and the shift in perceptions of virtual reality due to the growth of pseudo-immersive gaming worlds where users can directly interact with the environment and with others to build online social systems.

\section{Second Life}

Although it is far from ideal, one venue worth more examination is Second Life, an online world where users build and maintain the virtual landscape. Until this point, virtual reconstructions in archaeology were isolated, selfcontained, and only accessible through museum access points or CD-Roms. Second Life debuted in 2003, the creation of San Francisco based company Linden Lab as a place "where people could build whatever they liked, and become whoever they wanted" in an environment that was "more like a public park" than the more rigid, story-driven, persistent worlds of online games such as World of Warcraft and Everquest (Guest 2007:51-52). Since 2003, Second Life has grown to include over 15 million "residents" or uniquely named avatars with 83,000 of these residents owning almost 2 trillion square meters of virtual land. ${ }^{1}$ While owning land requires a premium membership with a monthly fee, basic membership is free and accessible to computer users with advanced graphics systems and a highbandwidth internet connection. After downloading the game software and creating an avatar through a relatively complex interface that allows the user to control all aspects of their online geometry (including relative eyebrow height, placement of the ears, and shoe size), Second Life is open to exploration by walking, running, driving, flying, ${ }^{2}$ or teleporting between areas. Most of the content in these areas is created by the user community and sometimes sold to other users, which has led to the development of a complex in-world economy that has a real-world economic impact due to dollars spent by individuals and corporations who want a presence in the world. The development of Second Life continues, with new releases adding features like voice chat, which allows users to actually speak to each other, instead of communicating by typing. These features have not only proven attractive to corporations, but also to nonprofit and educational entities that have access to the building tools of Second Life through a significantly discounted land-use rate.

Using the tools available in Second Life, the Open Knowledge and the Public Interest research group, (OKAPI) have digitally recreated Çatalhöyük, a Neolithic tell site located in Turkey, famously excavated by teams first led by James Mellaart in the 1960s and now by Ian Hodder. Hodder $(1997,2000)$ has encouraged a multivocal, reflexive engagement with the 
interpretation of Çatalhöyük, and to further this project, invited Ruth Tringham to excavate onsite in 1997. Tringham and the Berkeley Archaeologists at Çatalhöyük (BACH) continued to work at Çatalhöyük until 2005, excavating and digitally documenting a single structure, producing several short films, publications, websites, and a vast media database in the process (Tringham 2004, 2005; Tringham et al. forthcoming). The OKAPI team has drawn on this database to model Çatalhöyük in Second Life, duplicating an existing model of settlement, then opening up the island to alternate interpretations of space and architecture. The island hosts virtual events, digital collaborations in the form of mash-ups, and is the subject of an ongoing series of classes, administered by an undergraduate for other undergraduates. Archaeology in Second Life has also been explored by Shawn Graham, who used it as a tool to teach classes remotely. Michael Shanks participated in making a virtual museum installation for the San Francisco Modern Art Museum as well (Figure 1).

In the spring of 2008 I used the OKAPI-built model of James Mellaart's 1960 excavations to host the recreation of the interior of a room at Çatalhöyük. This was a fascinating exercise as an excavator, modeling features that I have methodically deconstructed over the years. The process of opening up the room led to several interesting archaeological questions. For example, after virtually plastering the interior of the reconstruction house, the sun set in Second Life, filling the house with evening light, illuminating the walls. The light soon became too dark to correctly model the platform I was working on, and I had to start considering the in- world time of day when choosing visual aspects of the reconstruction. As another example, when Ruth Tringham wanted to find the house containing the

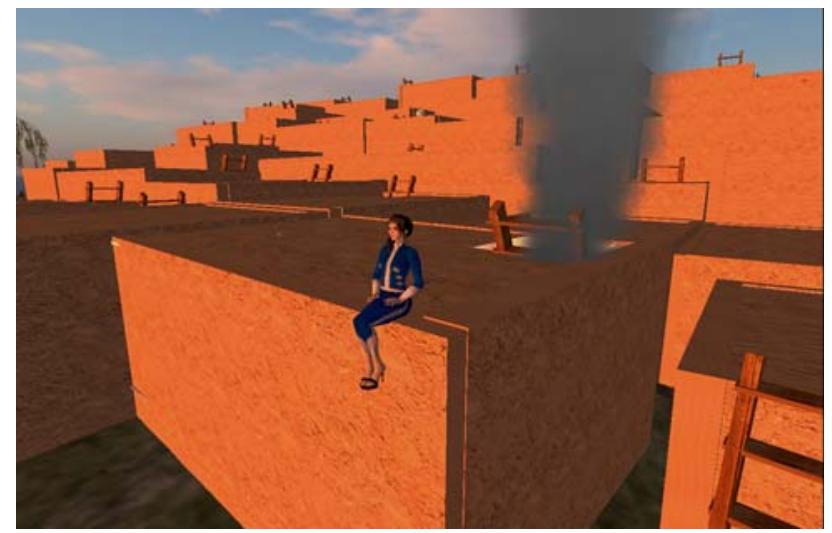

Figure 1. Sunset on virtual Çatalhöyük in Second Life 


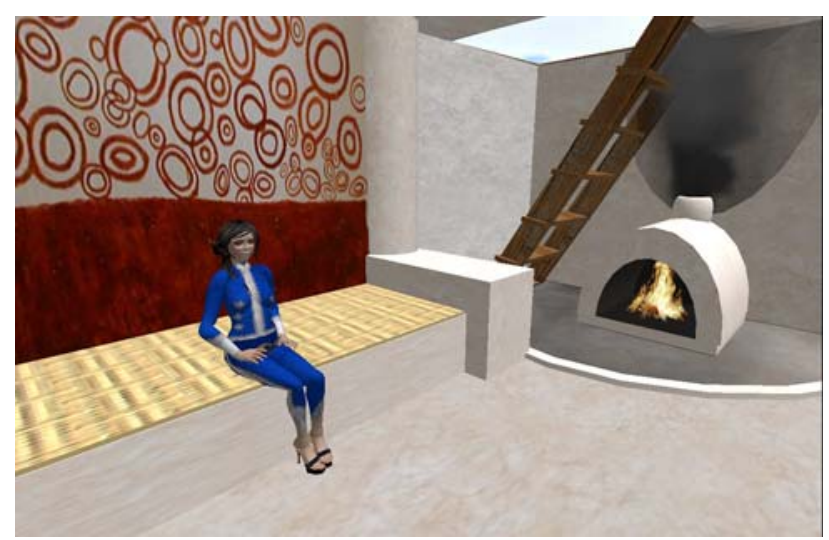

Figure 2. The reconstructed interior at virtual Çatalhöyük

reconstructed room among the dozens of nondescript, light brown structures, she wondered how people in the past might have distinguished between house exteriors and especially how each of the dwellings would be identified from the outside if one were unfamiliar with the community. This relatively limited exploration of the building tools available in Second Life encouraged further experimentation with presenting archaeological interpretations situated within a larger virtual world. It also provided insight into the goals and the methods of virtual archaeology, and into problems that are usually ignored in the implementation of these interpretations. Interacting with this medium provides a sharp contrast with other virtual reconstructions of sites. Certainly, Second Life would not be considered an appropriate, serious platform by many archaeologists interested in cultural heritage reconstructions. While Second Life should not be considered a perfect and unassailable tool for presenting archaeological information, it provides a way to critically engage and evaluate virtual sites. In what follows, I will outline three specific criticisms of traditional practice in virtual archaeology, as informed by experiments with Second Life. By laying out these criticisms, I hope to provide a framework for virtual reconstruction in archaeology as a meaningful medium and a platform for engagement and experimentation (Figure 2).

\section{Building}

First, the process and act of building within virtual worlds is important. Archaeologists cannot leave the construction of virtual sites in the hands of graphics specialists, but must learn the tools themselves. As previously 
mentioned, I recreated the interior of a room at Çatalhöyük using the relatively easy-to-learn tools in Second Life. The in-game creation engine is a modified CAD model, where the user manipulates geometric shapes, adding, subtracting, and piecing together the objects to achieve the desired results. This requires the archaeologist to approach artifacts, architecture, and the landscape from a different perspective; one that requires an additive, accretive process, breaking down the object into component parts instead of viewing excavated materials as a whole. For example, when I was creating an oven, a persistent and pervasive architectural feature that had been excavated repeatedly at Çatalhöyük, I struggled with the hard linearity of the Second Life building model; in building the square base of the oven I knew that in reality the plaster and mudbrick oven had rounded corners. When adding the roof of the oven, I had to decide how the smoke came out of the top, and how much, a topic that has been extensively debated at Çatalhöyük, as experimental archaeology has proven that smoke from the ovens would quickly fill these windowless, doorless dwellings. The responsibility to interpret the archaeological evidence was in my hands, made concrete by constructing a simple model of an oven. The significance of the observation and accurate interpretation of architectural details became more than an abstract necessity for the archive but a concrete force driving the subsequent gathering of visual materials and hereto unrecognized details that would aid the later implementation of a virtual model.

As a participant who is generally uninvolved in the final, "cooked" interpretation of the excavated materials at Çatalhöyük, making these interpretive decisions while recreating the room interior challenged my perceptions of the site, and made me truly engage with some of the questions that as an excavator I had pondered only in passing while filling out my data sheets. Further, I struggled with the lack of "correct" photographs for creating virtual textures. While there are over 50,000 photographs available in the site database, many of these photos were taken at oblique angles or obscured the texture of the object that I needed to use. For example, the photographs taken of entire buildings or features rarely showed a detailed, orthogonal view of plaster surfaces. After sculpting a plastered platform in Second Life, I found myself going back into the field with a new conception of site photography and took the shots that would prove to be useful later to reconstruct buildings in Second Life. Reconstructing buildings in Second Life changed the way that I interacted visually with the physical site, and the way I recorded features (Figure 3).

Increasing interpretive and methodological reflexivity as an archaeologist is only one part of the importance of building virtual reconstructions. There are other interpretations of the morphology of the architecture at Çatalhöyük, and OKAPI Island can host these multiple perspectives, preserving authorship in the "owner" tags of the object. Authors of Second 


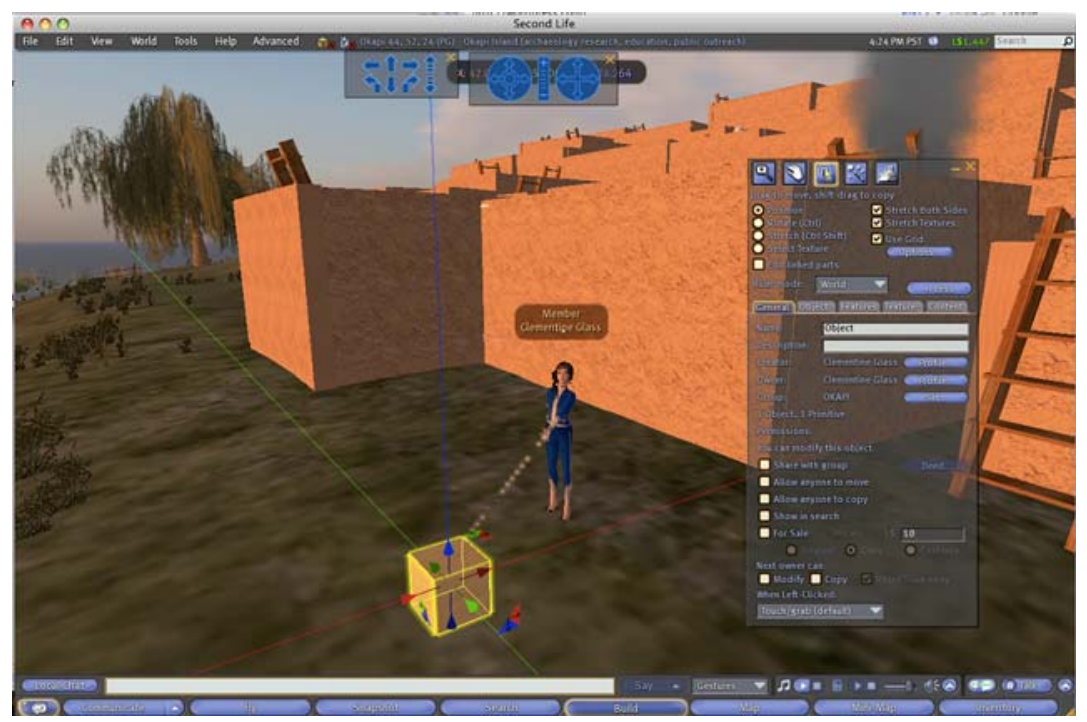

Figure 3. Object ownership and modification in Second Life

Life objects are guaranteed intellectual property rights, and Linden Lab encourages the use of Creative Commons licenses for these creations (Herman et al. 2006). Descriptions embedded in the object can provide more background and history, or mention possible uncertainties in the form and function that are extrapolated by the archaeologist. I can also allow my objects to be modifiable, enabling others to change my version of the oven, perhaps even "fixing" by altering the dynamics of the smoke and fire radically, if they choose. The objects can also be configured to allow direct copying, allowing other users to place their copy of the Neolithic oven in radically new contexts. Moreover, owners of land parcels can enable other Second Life players to build their own objects in what is called a "sandbox." In the case of OKAPI Island, this sandbox is near the other interpretations, and has hosted several interesting "remixes" of the information presented on the island about the site. The sandbox also draws other people to the island to build their own personal projects in the relative quiet of an educational environment. Visitors to archaeological sites in Second Life, whether archaeologists or not, can become agents of cultural production as they create their own in-game artifacts that "displace the traditional idea of the individual originating author" (Herman et al. 2006:194), a concept that most video games (and virtual reconstructions) preserve as unassailable. Participation in the past is not limited to a "look but do not touch," static, "correct" model, but can be commingled with modern 
objects, changed, and destroyed. This changeable, constructed past remains connected with the present day, an active, lived-in place that is part of a continuum.

However, these less restricted spaces can create unexpected issues: for example, an interesting social environment was created in spring of 2007 when virtual squatters had set up a parking lot high in the sky over OKAPI island. The new inhabitants left crushed hulks of virtual cars, half-built weapons and, oddly enough, empty soda bottles around the site. As stewards of virtual Çatalhöyük, we realized we had to enforce certain restrictions regarding the interpretation of the site, which were hereto unprepared to do. Still, opening the site even to a limited extent to those who are interested in virtual archaeological interpretations has been rewarding, and has led to the creation of Cultural Heritage in Second Life (CHiSL), an informal online consortium of archaeologists and cultural heritage experts who are interested in this medium as a form of interpretation and outreach. The members of this consortium employ different approaches; some of the sites are as realistic as the Second Life building engine will allow, employing video game designers and artists to create a structured experience, one closer to the more traditional purview of virtual reconstructions of archaeological sites. Other reconstructions, mine included, are less interested in accuracy exploring the limits of interactivity and interpretive potential.

\section{Accuracy}

This brings me to the second point, that accuracy is not especially important. As archaeologists, this statement can seem difficult to come to terms with, but in the case of virtual reconstructions, we should be not only interested in the end product, but in the process that leads to that product. I know that my poor oven would not pass the standards of even the most basic video game design, but making the oven and placing it into context, even a virtual context, has increased my engagement with the materiality of the objects and how they might have related to each other during their use-lives. As the smoke pours out of the top of the oven, I noted that not only the wall behind it would be stained, but the ceiling above, and the ladder to exit the building. After re-creating the room, I led a tour of it for multiple public archaeology days and used the example of the virtual room to talk about the actual site, pointing out the differences between the virtual version and the examples on site. In this way, the model is not meant to stand alone, complete, self-evident, and static. It is made to be engaged with, to be improved, to be disproved. The building tools are available to everyone who creates an account in Second Life. If a lackluster or incorrect 


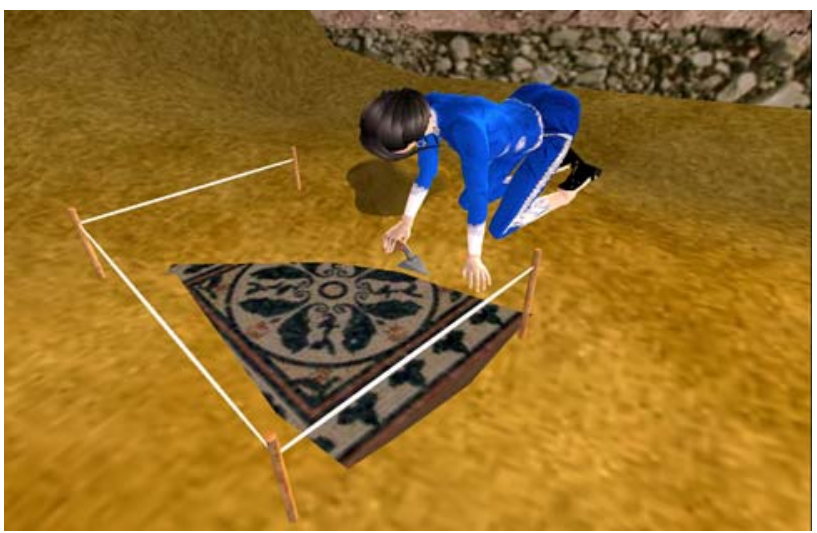

Figure 4. Excavating in Roma

representation of the past is encountered, the challenge is to create one's own, better interpretation. This interpretation inhabits a medium that is stylized in such a way as to remain decipherable to the residents, and perfect, photo-realistic accuracy is not only unachievable, but is undesirable and jarring to the greater visual fabric of the space. Archaeologists need not employ specialist designers, or become the most perfect 3D modelers in order to experiment with reconstructions. Second Life also provides an easy entry point for students to participate as active builders who subsequently become interested in paleoenvironments through questions provoked by populating an ancient landscape. Were there trees at Çatalhöyük? What did the Çarsamba river look like 9000 years ago? Is my reconstruction of the river deep enough? Without pressure to create an exact replica of an ancient settlement, students can have more control over their own creations and can debate and decide what they think, given the information provided to them (Figure 4).

\section{Avatars}

Finally, avatars are important. In most virtual archaeological reconstructions, the user is not allowed to choose their own identity or appearance. Their individual perspective is made generic, a sideline to the main attraction which is the reconstruction itself. How can a person begin to identify with an architectural reconstruction, if their own manifestation is unrecognizable to themselves? In Second Life, users can change gender, height, age, and ethnicity as easily as changing clothes, and many of them have several 
different "skins" that they don for different occasions. Much of the Second Life market appeals to this impulse, with customizable nuances such as eye color, nail polish color, and other minute aspects of avatars. Basic, readymade avatars are disdained by much of the Second Life population, instantly identifiable by their non-custom hair and generic clothes. While this may seem a pointless and frivolous aspect of online interaction, many users see it as a lack of commitment to the medium. Participation in the larger community of Second Life is an important part of interaction within the world, and elaboration of the basic avatars is an indication of interest in the platform. Moreover, the manipulation of avatars teaches basic building and in-world object manipulation, an important first step in becoming conversant with operating within Second Life.

Indeed, the creation of clothing in Second Life has introduced new questions to the interpretation of the material record. In contrast to artistic reconstructions, Second Life does not allow for obscurity in relevant details. Decisions about footwear, body markings, and necklines force the archaeologist to reconsider details about daily life and practice in the Neolithic. Add to this a seasonal element, and the complexity is dramatically increased. The avatars must negotiate the virtual landscape in their clothing, piloting boats, gathering willow branches, and tending fires, adding explicit considerations of maneuverability and visibility to the interpretation. While recreating one of the famous leopard-print bandeaus of Çatalhöyük, it occurred to me that what appears to be leopard print in figurines, may instead represent the repeated pattern of a stamp seal, applied to fabric. When forced to make interpretive decisions regarding details such as clothing or appearance, archaeologists can use Second Life as a creative venue to test different ideas based on their understanding of the remains of past peoples. ${ }^{3}$

Instead of viewing avatar creation as a barrier to the integration of archaeological information into venues such as Second Life, customizable avatars can add dramatically to the user experience. Most full-sized avatars cannot fit into the storage rooms at the reconstructed houses at Çatalhöyük, but children have no problem going inside and squeezing in the small spaces between some of the houses. In Roma, the large online reconstruction of Classical Rome, new users are encouraged but not required to don free togas and sandals. Much more than this simple costume play is the ability to embed actions into costumes and objects. While wearing an object, the avatar can perform certain preset actions that they would not be able to do without the object. A mano and metate, if activated, causes the avatar to sit down and start grinding at the stone. Trowels and sieves allow the avatar to excavate, accompanied by ongoing commentary-a train of virtual thought about the process-as the avatar finds pieces of plainware in the soil. Also as a corollary to the 
importance of avatars, NPCs in virtual archaeology should be abolished. NPCs are "non-player characters," entities generally created as a kind of set dressing, present to answer scripted questions about the reconstruction, or to provide ambiance. This tends to bring out the worst in reconstructive impulses; in one example, Julius Caesar reclines on his couch, reciting information about his villa to the user. A recent simulation of an African American site in Oakland, California contained prominent members of the community who stood by the side of the road to robotically impart their knowledge when approached by the user's avatar. Turning people of the past into mere mouthpieces for their architecture diminishes the rich potential of reconstructions to impart information about complex lifeways. Using programmable objects such as the previously mentioned mano and metate allows avatars to act as their own guides to the past, populating the re-created ancient landscape with avatars of people interested in the past, interacting with artifacts and taking on roles suggested by these artifacts. This is simple for archaeologists who are accustomed to telling stories through objects and adds another level of interactivity to the virtual reconstruction.

\section{Ongoing Work}

OKAPI Island is not the first virtual reconstruction of Çatalhöyük, nor will it be the last. In the mid-1990s, Martin Emele and Burkhard Detzler from Universität Karlsruhe worked to reconstruct rooms based on James Mellaart's drawings. They struggled with representations being too real, to the point that archaeologists complained that "the computer reconstruction has become so lodged in their minds that they no longer actually see what is front of them when excavating at the site" (Emele 2000:223). These simulations of Çatalhöyük provided "a deeper understanding of what it could have been to move around within and between the buildings at the site" and a virtual reconstruction was intended to provide a front-end interface for non-specialists to negotiate the site database (Hodder 1997). There was some additional concern that the reconstructions were too formal, and Hodder wanted "less sacred, less sterile, more animated" rooms with "pigs running around in them" (Emele 2000:224). This "dirtier" vision of life at Çatalhöyük can coexist with the sterile, sacred rooms of Mellaart, and elements from each can be mixed at will. This variety also allows for Tringham's sentiment that:

when we try to construct visual past realities—-whether by drawings, paintings, replications, photographs of replications, or computerized imagery-instead of trying to envision the past as lived, we try to envision the 
past as remembered by these various actors...Instead of presenting the past as a real (or Virtually Real) lived-in linear past that is experienced generically and normatively by all actors, we can present a past that is a dream or a memory, remembered piecemeal, selectively, and uniquely by the different actors (Joyce and Tringham 2007:341).

Learning from the "too real" reconstructions of the Karlsruhe team, and incorporating a multivocal approach, future virtual implementations of the settlement at Çatalhöyük should be built as a collaborative effort with archaeologists, students, and academics, and should not just serve as a place to experiment with archaeological interpretation, but also as a meeting place for past participants in the excavations, as well as an interested public. To this end, in fall of 2008, we continued work on OKAPI Island with a team of UC Berkeley undergraduates and Forensic Specialist Karl Harrison to virtually burn down part of the settlement. Using textures derived from burn marks apparent in the archaeology during the excavation of Building 77 in the 2008 summer field season we inferred the progressive stages of burning at the site using four dwellings. These reconstructions are accompanied by signs with written explanation, video taken onsite, and the presence of the archaeologists involved in the re-creation of the houses. This event attracted the attention of both the Second Life community and the larger public who are interested in archaeology at Çatalhöyük. In spring of 2009, undergraduates worked toward the creation of a machinima, or a movie made entirely within a virtual realm. The level of detailed required to recreate scenes from the past pushed the medium of Second Life even further. OKAPI Island continues to grow and change, with each project adding to the virtual palimpsest of the virtual Çatalhöyük.

\section{Conclusion}

Second Life is not perfect by any measure. Placing an archaeological reconstruction into a world outside of the strict setting of a museum requires an ongoing engagement with the site-it is not enough to build a monument and move on to the next project. Population density is relatively sparse and areas can seem utterly depopulated unless specific events are scheduled for the space. While this makes Second Life unattractive to many large, corporate sponsors (Rose 2007), it continues to attract educators and hobbyists who have used the in-world building tools to re-create historical sites ranging from Teotihuacán, to Troy and the Great Wall of China. Use of these sites varies; some are glorified honeymoon destinations reconstructed 
as romantic backdrops for avatar couples whereas others are more seriousminded venues for the promotion of cultural heritage tourism. Just as often these projects are created by academic institutions as a one-off event, launched, and then abandoned. The Sistine Chapel re-created by Vassar in 2007 created a sensation due to the incredible amount of detail employed, but has not been elaborated upon since then, nor does it offer much history or background of the structure. Many of these sites show signs of neglect, much like heritage sites that have been left in disrepair in the real world. Finally, the sustainability of these virtual sites is also questionable, as students graduate, academics shift in interest, and funding runs out. As of 2008, OKAPI island costs $\$ 1800$ per year for land-use, an expense that cannot be maintained perpetually without significant supporting institutional infrastructure. Objects created in Second Life are generally untranslatable to other platforms, and reconstructions that run out of funding can face serious data loss.

At this point in time, virtual archaeology has an incredible array of technological resources to draw from and this will only increase as reconstructive technology becomes less expensive and more pervasive. The temptation to use the top of the line, highest-quality graphics hardware and software is difficult to resist, and the images created by the investment in this technology obscure the line between real and virtual, and the archaeological and the imaginary, in an ever expanding and fascinating manner. Archaeologists are only recently coming to an understanding of the implications of the transformation of archaeological remains into visual representations of our data, and how these representations change our theory and practice.

Using preexisting tools within realms already inhabited by the public and opening the past up to multiple interpretations lowers the investment in technological know-how for the archaeologist and eliminates the problems with interpretive transparency. It also does away with the need to create one-dimensional, three-dimensional virtual inhabitants who have a limited range of speech, thought, and actions. Juxtaposing excavations, recreations, and active interpretations provides a much broader range of archaeological information, and the ability to chat with an archaeologist gives the public unprecedented access to the archaeological process. Additionally, online communities such as Second Life provide a discursive "third space" where informal sociability can occur between teachers and students, as encouraged by Friere's approach to pedagogy (Steinkuehler and Williams 2006). More projects that put archaeological information in the virtual path of the public instead of more passive interpretive schemes will lead to a greater visibility of archaeological projects. 


\section{Notes}

1. Statistics released by Linden Labs as of September 2008.

2. Flying can be restricted by land owners, and some historical reconstructions enforce this to provide an appropriate setting.

3. Speculation regarding the clothing of the denizens of Çatalhöyük owes a large debt to the art of John Swogger and Katheryn Killackey.

\section{Open Access}

This article is distributed under the terms of the Creative Commons Attribution Noncommercial License which permits any noncommercial use, distribution, and reproduction in any medium, provided the original author(s) and source are credited.

\section{References Cited}

Bassett, C.

1997. Virtually Gendered: Life in an On-Line World. In The Subcultures Reader, edited by K. Gelder and S. Thornton, pp. 537-550. Routledge, London.

Benko, H., E.W. Ishak, and S. Feiner

2004. Collaborative Mixed Reality Visualization of an Archaeological Excavation. Paper presented at the Third IEEE and ACM International Symposium on Mixed and Augmented Reality, Arlington, VA.

Crary, J.

1990. Techniques of the Observer: On Vision and Modernity in the Nineteenth Century. MIT Press, Cambridge, MA.

Dery, M., and P. Lamantia

1993. Culture Jamming: Hacking, Slashing and Sniping in the Empire of Signs. Open Media, Westfield, NJ.

Emele, M.

2000. Virtual Spaces, Atomic Pig-bones and Miscellaneous Goddesses. In Toward Reflexive Method in Archaeology: The Example at Çatalhöyük, edited by I. Hodder. McDonald Institute for Archaeological Research, Cambridge.

Forte, M., and A. Siliotti

1997. Virtual Archaeology: Re-creating Ancient Worlds. H.N. Abrams, New York.

Frischer, B., F. Niccolucci, N.S. Ryan, and J.A. Barcelo

2002. From CVR to CVRO: The Past, Present, and Future of Cultural Virtual Reality. In Virtual Archaeology: Proceedings of the VAST Euroconference, Arezzo 24-25 November 2000, edited by F. Niccolucci. Archaeopress, Oxford. 
Goldberg, K.

1998. Virtual Reality in the Age of Telepresence. Convergence: The International Journal of Research into New Media Technologies 4(33):33-37. doi:10.1177/ 135485659800400105.

Goodrick, G., and G. Earl

2004. A Manufactured Past: Virtual Reality in Archaeology. Internet Archaeology Winter(15).

Goodrick, G., and M. Gillings

2000. Constructs, Simulations and Hyperreal Worlds: the Role of Virtual Reality (VR) in Archaeological Research. In On the Theory, Practice of Archaeological Computing, edited by G. Lock and K. Brown, pp. 41-58. Oxford University School of Archaeology, Oxford.

Guest, T.

2007. Second Lives: A Journey Through Virtual Worlds. Random House, New York.

Herman, A., R.J. Coombe, and L. Kaye

2006. Your Second Life?. Cultural Studies 20(2):184-210. doi:10.1080/0950238 0500495684 .

Hillis, K.

2006. Modes of Digital Identification: Virtual Technologies and Webcam Cultures. In New Media Old Media: A History and Theory Reader, edited by H.K. Chun and T. Keenan. Routledge, New York.

Hine, C.

2000. Virtual Ethnography. Sage, London.

Hodder, I.

1997. 'Always Momentary, Fluid and Flexible': Towards a Reflexive Excavation Methodology. Antiquity 71:691-700.

2000. Towards Reflexive Method in Archaeology: The Example at Çatalhöyük. McDonald Institute Monographs, McDonald Institute for Archaeological Research, University of Cambridge; Distributed by Oxbow Books, Cambridge.

Joyce, R.A., and R. Tringham

2007. Feminist Adventures in Hypertext. Journal of Archaeological Method and Theory 14(3):328-358.

Kantner, J.

2000. Realism vs. Reality: Creating Virtual Reconstructions of Preshitoric Architecture. In Virtual Reality in Archaeology, edited by J.A. Barcelo, M. Forte, and D.H. Sanders. British Archaeological Reports. vol. S843. Archaeopress, Oxford. 
Kendall, L.S.

1998. Hanging Out in the Virtual Pub: Identity, Masculinities, and Relationships Online. Thesis Ph D, University of California Davis.

Krasniewicz, L.

2000. Immersive Imaging Technologies for Archaeological Research. In Virtual Reality in Archaeology, edited by J.A. Barcelo, M. Forte, and D.H. Sanders. British Archaeological Reports. Archaeopress, Oxford.

Lister, M., J. Dovey, S. Giggings, I. Grant, and K. Kelly

2002. New Media: A Critical Introduction. Routledge, New York.

Lock, G.

2003. Using Computers in Archaeology. Routledge, London.

Manovich, L.

2001. The Language of New Media. Massachusetts Institute of Technology, Cambridge.

Mirzoeff, N.

1999. An Introduction to Visual Culture. Routledge, London.

Morse, M.

1998. Virtualities: Television, Media Art, and Cyberculture. Indiana University Press, Bloomington.

Reilly, P.

1990. Towards a Virtual Archaeology. In Computer Applications in Archaeology, edited by K. Lockyear and S. Rahtz. British Archaeological Reports, Oxford.

1992. Three-dimensional Modelling and Primary Archaeological Data. In Archaeology and the Information Age: A global perspective, edited by P. Reilly and S. Rahtz. Routledge, London.

Robins, K.

1996. Into the Image: Culture and Politics in the Field of Vision. Routledge, London.

Rose, F.

2007. How Madison Avenue is Wasting Millions on a Deserted Second Life. In Wired. vol. 15. Monthly vols.

Rucker, R.v.B., R.U. Sirius, and Q. Mu

1992. Mondo 2000: A User's Guide to the New Edge. 1st ed. HarperPerennial, New York, NY.

Slator, B.M., J.T. Clark, J. Landrum III, A. Bergstrom, J. Hawley, E. Johnston, and S. Fisher

2001. Teaching with Immersive Virtual Archaeology. Paper presented at the Seventh International Conference on Virtual Systems and Multimedia, Berkeley, CA. 
Steinkuehler, C., and D. Williams

2006. Where Everybody Knows Your (Screen) Name: Online Games as "Third Places". Journal of Computer-Mediated Communication 11(4):1.

Sutherland, I.E.

1968. A Head-Mounted Three-Dimensional Display. Paper presented at the Proceedings of the Fall Joint Computer Conference, Washington, DC.

Terras, M.M.

1999. A Virtual Tomb for Kelvingrove: Virtual Reality, Archaeology, and Education. Internet Archaeology (7).

Tringham, R.

2004. Interweaving Digital Narratives with Dynamic Archaeological Databases for the Public Presentation of Cultural Heritage. In Enter the Past: The E-way into the Four Dimensions of Cultural Heritage-CAAA2003, edited by W. Borner and W. Stadtarcheologie. Archeopress, Oxford, UK.

2005. Archaeology on the Web: Entanglement and Entrapment or Medium for Limitless Creativity and Communication? In Archaeology and the Internet, pp. 98-111. London.

Tringham, R., M. Ashley, and S. Mills

forthcoming. Senses of Places: Remediations from Text to Digital Performance. Visual Anthropology Review.

Woolley, B.

1992. Virtual Worlds: A Journey in Hype and Hyperreality. Blackwell Publishers, Oxford. 